\title{
The hemiplegic arm after stroke: measurement and recovery
}

\author{
DT WADE, R LANGTON-HEWER, VA WOOD, CE SKILBECK, HM ISMAIL \\ From the Stroke Recovery Research Unit, Department of Neurology, Frenchay Hospital, Bristol, UK
}

SUMMARY Seven clinical tests have been used to study the recovery of arm function in 92 patients over 2 years following their stroke. These tests are simple and quick, and can be used by any interested observer. They form a hierarchical scale that measures recovery. Statistically significant improvement is only seen in the first 3 months. Fifty-six patients initially had nonfunctional arms; eight made a "complete recovery" and 14 a partial recovery. The tests described are inadequate on their own because they are not sufficiently sensitive at the upper range of ability. While recovery of lost function does relate to the degree of initial neurological loss in the arm, it seems to be largely independent of the overall severity of the stroke.

Recovery after stroke can be measured in many ways, and the method chosen will depend upon the information wanted. Survival apart, the simplest ways can include the length of stay in hospital and final "placement" (type of accommodation), but these depend upon social factors as much as upon the degree of physical recovery. "Activities of Daily Living" (ADL) scales (for example the Barthel ${ }^{1}$ ) relate much more to the patient alone, and have practical and prognostic value. However, using these scales it is difficult to separate the recovery of specific lost neurological function from a more generalised adaptive response.

The study of isolated arm function might allow measurement of the recovery of lost neurological ability separate from the adaptive response adopted using preserved functions (for example, learning to eat and dress one-handed). If so, one could assess the effect of therapeutic intervention (for example, physiotherapy) upon recovery itself. In addition, it could help provide a prognosis for recovery.

Arm function after stroke has been measured previously,,$^{2-5}$ but no single technique has become generally used. Previous methods have either depended upon special equipment, ${ }^{2}$ or required time consuming assessments ${ }^{3-5}$ to be made. Therefore these techniques cannot easily be used in large scale

Address for reprint requests: Dr $\mathrm{R}$ Langton-Hewer, Dept of Neurology, Frenchay Hospital, Bristol BS16 1LE UK.

Received 17 December 1982

Accepted 1 February 1983 follow-up studies. There is a need for a simple method of measuring arm function that can be used upon a wide range of patients by any interested observer using the minimum of equipment. This paper reports upon a method that has been used in a long-term follow-up study on all patients referred to the Frenchay Stroke Unit over the 2 years 1976-78.

\section{Patients}

One hundred and sixty two patients were accepted by the Unit, a specialist rehabilitation department; all referrals were accepted provided that the patient lived in or near the district, and were fit enough to attend. The total includes not only patients admitted to the hospital but also 44 acute strokes who were never admitted to hospital but received all their treatment as out-patients.

Ninety two of the 101 patients who survived to their final follow-up were assessed, and they form the basis for the results, except where stated otherwise. There were 45 men and 47 women; 49 had a right hemiplegia, 41 a left hemiplegia, and two had "brain-stem" strokes. The mean age of the 92 was 66.5 years (SD 9.1, range 47-86). Patients were seen as soon as possible after their stroke; $20 \%$ were seen within 1 week and $82 \%$ within 3 weeks. Thereafter patients were seen at $1,3,6,12$, and 18 months after the stroke, and then finally at $2(n=55)$ or $3(n=37)$ years after the stroke. The assessments were done by therapists as part of their normal work. Because staff changed during the study, no special training was given although guidance notes were available. Patients were assessed whether or not they were still under active treatment, but occasionally patients missed a few assessments and the numbers receiving a full assessment at each point are shown as part of 
Table 1 Arm function tests

1. Use both hands to open jam jar.

2. Use both hands to rule a line.

3. Use affected hand to pick up and release $2^{\prime \prime}$ cylinder.

4. Use affected hand to pick up and release $1 / 2$ " cylinder.

5. Use affected hand to drink water from glass.

6. Use affected hand to comb hair.

7. Use affected hand to open and close clothes peg.

Score 1 for each one passed

Table 2 Pass rate for individual tests

\begin{tabular}{|c|c|c|c|c|c|}
\hline $\begin{array}{l}\text { Time afier } \\
\text { stroke }=\end{array}$ & $3 w k$ & 3 mth & $6 \mathrm{mth}$ & $12 \mathrm{mth}$ & $2-3 y r$ \\
\hline $\begin{array}{l}\text { Test no. } \\
1 \\
2 \\
3 \\
4 \\
5 \\
6 \\
7\end{array}$ & $\begin{array}{l}\text { No pa } \\
37 \\
34 \\
29 \\
30 \\
20 \\
16 \\
21\end{array}$ & $\begin{array}{l}\text { ng each } \\
39 \\
41 \\
36 \\
36 \\
29 \\
27 \\
27\end{array}$ & $\begin{array}{c}\text { ndividual } \\
57 \\
57 \\
51 \\
49 \\
44 \\
34 \\
42\end{array}$ & $\begin{array}{l}\text { test } \\
53 \\
55 \\
50 \\
49 \\
47 \\
42 \\
47\end{array}$ & $\begin{array}{l}50 \\
50 \\
51 \\
51 \\
47 \\
44 \\
46\end{array}$ \\
\hline Total $^{*}=$ & 72 & 63 & 80 & 79 & 84 \\
\hline
\end{tabular}

table 2. A few more patients were seen but had incomplete assessments and were only recorded as having fully (score 7), partly (score 2-6) or non-functional (score 0-1) arms.

\section{The tests}

The ideal clinical measure should be: (a) Simple to apply, both for the patient and the observer, (b) Sensitive throughout the whole range of potential function, (c) Applicable to patients with all grades of disability.

Two general approaches are possible. First: one can use a series of graded tasks, reflecting the accepted order of recovery and each one scored simply as pass or fail. The series should cover the whole range of ability. Second: one can take a single activity and measure its performance accurately (for example, the rate of finger tapping has been used to follow recovery after head injury ${ }^{6}$ ).

This study used the seven graded tasks shown in table 1 . The patient scored 1 for each test passed, giving a scale ranging from 0 to 7 .

\section{Results}

THE SCALE

The number of people passing each test at 5 assessment points is shown in table 2 , together with the total number of people assessed at each time. By summing along each row one can see that the overall order of passing the tests is $2,1,3,4,5,7,6$. Consideration of the pass rate at each assessment point confirms the overall order. However, tests $1 \& 2$ and tests 3 \& 4 are always close (and sometimes in reverse order). Thus it is likely that five tests could equally well cover the range: 1 (or 2 ), 3 (or 4), 5, 7, and 6.

Further analyses confirmed the hierarchy of these tests. Firstly, passing any one test is almost always associated with passing all the easier tests. Secondly. study of individual patient's records again shows that recovery of the ability to pass individual tests returns in the order given.

\section{RECOVERY AFTER STROKE}

Fifty-five of the 92 patients were fully assessed at each point. They did not differ significantly from the whole group, and their mean and median arm function scores are plotted in fig 1 . It can be seen that

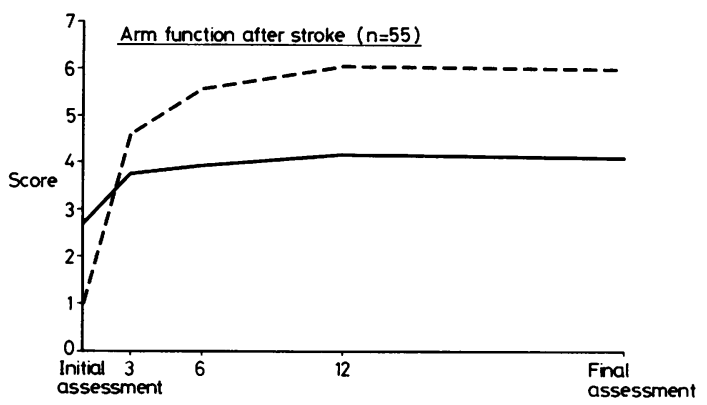

Fig. Recovery of arm function after stroke.

- median

- mean

there is considerable improvement over the first 3 months, and further analysis using the Wilcoxon signed-rank test ${ }^{7}$ shows that this is statistically significant $(p<0.001)$. The later improvement is not statistically significant for the group as a whole, but it is discussed later.

It is important to realise that this summary statistic hides one important feature. Table 3 records the number of patients achieving a particular total score

Table 3 Arm function scores in 55 patients assessed at every point

\begin{tabular}{llrrrr}
\hline $\begin{array}{l}\text { Time after } \\
\text { stroke }\end{array}$ & $\begin{array}{l}\text { Initial } \\
\text { Assess- } \\
\text { ment }\end{array}$ & 3 mth & 6 mth & 12 mth & $\begin{array}{l}\text { Final } \\
\text { Assess- } \\
\text { ment }\end{array}$ \\
\hline Total score & & & & & \\
$0 / 7$ & 25 & 19 & 17 & 18 & 20 \\
$1 / 7$ & 3 & 3 & 3 & 2 & 1 \\
$2 / 7$ & 2 & 0 & 3 & 2 & 0 \\
$3 / 7$ & 2 & 2 & 2 & 0 & 1 \\
$4 / 7$ & 5 & 3 & 0 & 0 & 0 \\
$5 / 7$ & 5 & 3 & 2 & 3 & 2 \\
$6 / 7$ & 2 & 3 & 4 & 3 & 4 \\
$7 / 7$ & 11 & 22 & 24 & 27 & 27 \\
\hline
\end{tabular}


at each time. It shows that by the final assessment only eight patients have a score other than 0 or 7 . Examination of table 2 shows that there is little difference between the number passing the easiest and the most difficult test at any particular assessment point. At the final assessment this difference amounts to $8 \%(7 / 84,51$ passed test 3 and 44 passed test 6 ). Therefore there is clearly a bi-modal distribution of scores and this is apparent, although less obvious, even at the initial assessment.

Fifty-six of the 92 patients initially had "nonfunctional" arms (score 0 or 1). By final follow-up, eight had made a complete recovery (score $7 / 7$ ), and 14 a partial recovery (score 2-6/7), leaving 34 still with non-functional arms. In order to identify features indicative of a good prognosis, the 34 with no recovery have been compared with the 22 who made at least some recovery (complete or partial).

Of 25 variables recorded at the initial assessment, only three individually correlated with poor recovery. The first two, the initial motor deficit in the arm (chi-square $=5.74, p<0.02$ ) and loss of position sense in the arm (chi-square $=8.16, p<0.02)$ both measure the severity of the initial loss of arm function. The third, the Camden mental scale ${ }^{8}$ score $(t=$ $3.8, p<0.01)$, is more a test of overall cerebral function. The correlation between initial Camden score and final arm function score is little affected by partialling out the initial severity of stroke. Other variables usually considered indicative of the severity of the stroke (for example, the initial Barthel ${ }^{1}$ score, urinary incontinence, loss of sitting balance) did not correlate with arm recovery, nor did specific measures of the loss of "leg function" (for example, motor deficit in the leg, loss of position sense in the leg).

Stepwise multiple regression using the WherryDoolittle technique 9 is an alternative method of identifying a few independently prognostic indicators from among a large number of variables. Using this technique on 69 patients to predict arm function score at 12 months, we found that the most important prognostic variable was the degree of initial motor deficit in the arm. The degree of flaccidity in the arm was the second most important, and the only other variable selected was the patient's initial walking status.

Change does occur in some patients after 3 months. In the complete sample, six patients improved by two or more points between 3 and 6 months. One of these six, plus another four patients, improved by the same amount between 6 months and 1 year. One person deteriorated between 6 months and 1 year, but after 1 year four deteriorated by two or more points while only one improved by the same amount.

\section{Discussion}

The scale described is simple and can easily be used by therapists in the course of their normal work. It does not require any unusual equipment or specific training. It is a hierarchical scale and does measure the improvement of arm function after stroke, both in a group of patients and in individual patients. However, the scale appears to lack sensitivity at the upper range of arm function. Using this scale, patients are finally divided into two groups-those whose arms remain useless, and those who achieve the top score-with few having an intermediate score. It is unlikely that recovery is in fact such an all-or-none phenomenon, and other studies ${ }^{4} 5$ have found intermediate levels of recovery. The probable explanation for this observation is that our scale cannot detect improvement at the upper end.

This "ceiling effect" is a problem associated with scales that depend upon categorising one or more tests and then calculating a score (for example, it also occurs with the Barthel ADL scale when used to measure recovery after stroke ${ }^{10}$ ). When constructing tests it is difficult to devise pass or fail tests that are sufficiently sensitive to detect change at the upper end of ability. Equally it is difficult to find a single measured activity that can span the whole range of disability with sufficient sensitivity. This lack of sensitivity at the extremes of function probably also accounts for the "basement" effect, with so many patients appearing to make no recovery. However, this is less of a practical problem as minor recovery in a nevertheless useless arm is of little practical significance.

There are two ways of overcoming this problem. First, one can use both approaches mentioned above, retaining pass/fail tests for use at the lower range, and a measured activity (for example, rate of finger tapping) at the upper range. A few patients in this study had hand-grip strength measured using a dynamometer and they did show continuing improvement. However, it can be difficult to combine two scales to give a single score. The second method is to measure the performance of each of the tests (for example, timing them, or having more categories than simply pass or fail ${ }^{5}$ ), with a suitable cut-off point to identify those who cannot perform the test at all. This can give a single score.

Recovery of arm function after stroke is concentrated in the early months, and this finding is in agreement with other studies both upon arm function, ${ }^{3-5}$ and upon general function. ${ }^{10}{ }^{11}$ There is a plateau after six months, but both in our study and in others ${ }^{3-5}$ it is possible to find some patients who show later improvement.

It is encouraging that $14 \%$ of those with initially 
non-functional arms made a good recovery, and a further $25 \%$ a partial recovery. Of 25 clinical features noted at the first assessment, only five were related to this recovery, and three of these were direct measures of the original loss of arm function. The fourth, the patient's mental performance, may well reflect pre-existing general cerebral deterioration rather than the severity of the stroke itself. The last, loss of walking ability, does reflect upon the overall severity of the stroke itself but its contribution carried the least weight.

Thus, recovery of arm function seems to be very largely independent of the overall severity of the stroke (for example, as judged by the initial Barthel score or worst Rankin ${ }^{12}$ grade). Rather, recovery would seem to depend mainly upon the initial degree of loss in the arm itself, both motor and sensory. This was also found in a recent study. ${ }^{13}$

The study of the return of arm function after stroke should allow more direct measurement of specific neurological recovery (as distinct from the measurement of the overall adaptive response). Most studies on recovery after stroke have used ADL scales, which measure the ability of the patient to perform certain tasks but do not specifically measure the function of the affected limbs. Many of these ADL activities can be performed in the presence of very poor actual recovery of function on the affected side, provided that the patient learns new ways of performing the tasks (for example, a patient can walk on a rigid leg and can feed and wash onehanded). Further development of simple clinical tests such as these would greatly aid the study of recovery following stroke.

This work was generously supported by the Chest, Heart \& Stroke Association.

\section{References}

${ }^{1}$ Granger CV, Sherwood CC, Greer DS. Functional status measures in a comprehensive stroke care program. Arch Phys Med Rehabil 1977;58:555-61.

${ }^{2}$ De Souza LH, Langton-Hewer R, Miller S. Assessment of recovery of arm control in hemiplegic stroke patients. 1. Arm function tests. Int Rehab Med 1980;2:3-9.

${ }^{3}$ Bard G, Hirschberg GG. Recovery of voluntary motion in upper extremity following hemiplegia. Arch Phys Med Rehabil 1965;46:567-72.

${ }^{4}$ Fugl-Meyer AR, Jaasko L, Leyman I, Olsson S, Steglind $\mathrm{S}$. The post-stroke hemiplegic patient 1. A method for evaluation of physical performance. Scand J Rehab Med 1975;7:13-31.

${ }^{5}$ Carroll D. Hand function in hemiplegia. J Chron Dis 1965;18:493-500.

${ }^{6} \mathrm{Klonoff} \mathrm{H}$, Low MD, Clark C. Head injuries in children: a prospective five year follow-up. J Neurol Psychiatry 1977;40:1211-9.

${ }^{7}$ Siegel S. Nonparametric statistics for the behavioural sciences. Tokyo: McGraw-Hill 1956.

${ }^{8}$ Denham MJ, Jeffreys PM. Routine mental testing in the elderly. Modern Geriatrics 1972;2:275-9.

- Garrett HE. Statistics in psychology and education. Chapter 16. London: Longmans 1958.

${ }^{10}$ Skilbeck CE, Wade DT, Langton-Hewer R, Wood VA. Recovery after stroke. J Neurol Neurosurg Psychiatry 1983;46:5-8.

${ }^{11}$ Andrews K. Brocklehurst JC, Richards R, Laycock PJ. The rate of recovery from stroke-and its measurement. Int Rehab Med 1981;3:155-61.

${ }^{12}$ Rankin J. Cerebral vascular accidents in patients over the age of 60: II. Prognosis. Scott Med J 1957;2:200 15.

${ }^{13}$ Kusoffsky A, Wadell I, Nilsson BY. The relationship between sensory impairment and motor recovery in patients with hemiplegia. Scand $J$ Rehab Med 1982;14:27-32. 